Vol. XXV No $2 \quad 2019$

\title{
METHODOLOGICAL GUIDELINES FOR THE TECHNICAL TRAINING OF JUDO PLAYERS IN THE MILITARY SYSTEM
}

\author{
Robert STĂNCIULESCU*, Cristian STĂNCIULESCU**, Elvira BELDIMAN*** \\ *“Nicolae Bălcescu” Land Forces Academy Sibiu, Romania \\ ** The Police Inspectorate of Sibiu, Romania \\ *** Bucharest Bar Association, Romania \\ rstanciulescu@armyacademy.ro, stanciulescu_cristian87@yohoo.com, \\ avoelvira@.co.uk
}

\begin{abstract}
Judo, a sport playing a vital role in the training of the military, leads to the achievement of positive, multiple and unique effects, both in terms of developing the motor skills, but also in the formation, consolidation and improvement of applicative skills and aptitudes specific to close combat. The paper highlights the fact that the methods and contents specific to combat sports represent a useful and effective way of meeting the formative objectives in the context of the current Romanian Army missions, facilitating the physical adaptation of the combatants to the new demands imposed by the modern battlefield, characteristic of the actions carried out by NATO military structures.
\end{abstract}

\section{Keywords: sport, combat, judo, means, missions}

\section{Introduction}

The successful fulfillment of the increasingly complex missions characteristic of recent military actions involves planning, organizing and carrying out a complex process of training whose duration is determined by the training objectives, the training level of the fighters, their psychophysical qualities, as well as the pedagogical mastery of the specialists. A basic pivot of the training of the fighters, physical education, through the means and methods used to assure an adequate physical and psychic potential, includes among the disciplines that contribute to the achievement of this objective, the judo, mainly pursuing the formation and improvement of applicative skills and aptitudes, used in military actions involving close combat. Really contributing to the increase of combatants' combatance by developing the basic motor skills, the psychic qualities of coordination and self-challenge in the face of factors that cause pain and fear, the courage and confidence in their own forces, judo forms skills and develops the qualities needed to successfully carry out battles, isolated or in group, and undoubtedly contributes to providing a developed biopsycho-motor support that can ensure success if it is well-capitalized [1]. The judo procedures used in the training of fighters are chosen so that they can be adapted and used in all the complex and difficult situations that appear on the battlefield and which the fighter needs to show spontaneity, such as: 
falls, imbalances, rollings, projections, fixations, strangulations and articulation techniques, thus forming the skills to attack, block and timely counterattack with the naked hand or with the individual weapon against one or more opponents. The specialists' preoccupations with regard to the most appropriate technical procedures that need to be suited and adapted to the demands imposed by the battlefield involve the observance of pedagogical principles that ensure the use of the most appropriate teaching methods and means of action, able to make the most of the opportunities emerging within the military actions.

\section{The system of teaching the judo techniques}

The component with the highest specificity in all sport disciplines, the technique mainly seeks to maximize the specific motor actions for their optimum execution and achievement of the expected performance. In other words, the technical training represents a system of motric structures specific to each sport discipline, performed rationally and economically, in order to obtain a maximum return. The technique is different, depending on the sport discipline in which it is used, and even within the same discipline from one element to another [3]. Conditioned to a great extent by the level of development of basic motor skills, basic motor and applicative pragmatic aptitudes, technical training is closely correlated with tactical training, psychological training and theoretical training. The possibilities of the military personnel to adapt to the increasingly complex demands that combat imposes depend very much on its quality.

\subsection{Technical training - an essential component of performance in judo}

The diversity of the technical elements and procedures specific to combat sports, in general, and to judo, in particular, demand special attention in the ample and complex process of military fighters' training for the perfect acquisition of all the technical procedures that have to be learnt. The technical training consists of the following elements [2]:

- the technical element of specificity represents a fundamental motor structure lying at the foundation of the practice of a sport discipline. The technical element characterizes a certain sport discipline, being different from one discipline to the other even if the technical structures are similar;

- the technical procedure that designates a concrete motor structure or the particular way of carrying out the technical element;

- the style of execution is the particular way of executing a technical procedure, being a finesse characteristic that most of the times ensures higher performance;

- the basic mechanism of the technical procedure represents the logical succession of motor actions, objectively necessary in order to be efficiently carried out.

The technical training is an essential component of the specific training, which is done in several stages, as follows:

a) the stage of getting information and of the formation of the movement representation in which the conception and the basics of the procedure to be learnt are acquired.

The information can be verbal, transmitted accurately, with the role of forming an initial image of the action that is to be taken, visual, having the role of reinforcing the image by using films, photos or any other type of means that come up with the visual information for those who execute the actions, as well as tactile-kinesthetic information, required in the complex technical executions of great risk that have the role of providing safety, of enhancing confidence. The capitalization of information supposes a very good perception, based on attention, concentration, sensorial qualities, 
and their amount has to take into consideration the fighters' characteristics.

b)The stage of coarse or insufficiently differentiated movements, characteristic of the first practical execution of the respective technical process, in which the main information received by the subjects consists of verbal indications. This stage is crucial in the proper learning of the technique. If mistaken motors with inappropriate trajectories or inappropriate amplitudes are used, they make up as many mistakes, which will later be very difficult to correct. Therefore, special motoring measures (use of aids, restrictive procedures) and methods to promote correct exercise are required. These will mainly refer to the components of the basic mechanism of the technical process.

c) The stage of fine coordination and consolidation of technical procedures has as essential features: the correct execution of movement, usually under various standard or "stereotype" conditions (only in certain situations, reduced in number); the execution with increased indexes of force, speed and resistance; fluent execution with appropriate rhythm, accuracy and amplitude. Effective at this stage are the indications of perception and sense of movement, as this information can be directly and coordinately transposed by the subjects. Particular attention will be paid to the formation of perceptions, with special reference to the internal processes of motricity: perfection of differentiated perceptions, of kinesthetic-vestibular responses, as well as the intensive engagement of performance premises conditioned from a coordinative point of view.

d) The stage of the improvement and overlearning of the technical process is characterized by its performance in various conditions, with higher efficiency indexes, knowing that over-learning is an effect and a condition determined by the need for a large number of repetitions.

\subsection{Methodological guidelines on learning and improving judo techniques}

It is extremely important for the specialists to take into account the following elements in the training process for learning and improving the judo technique:

- avoiding too much information, which, even in the form of explanations and demonstrations, cannot be assimilated in a short time. It is necessary that this information should be provided in time, progressively, according to the principle from simple to complex and from known to the unknown, requiring a careful analysis of the indications and maintaining only those with immediate effects.

- knowledge of the condition of the fighters' body by monitoring the existing conditions and switching to other types of activities in the event of fatigue symptoms, as increased physical fatigue manifested by decreased effort capacity or coordination in general reduces the capacity for assimilation and control.

- the transmission of clear and complete information, because incomplete information (verbal and intuitive) does not form a clear representation of the technical process or motor act to be executed.

With regard to the differentiation of the content of the judo training stages, it is necessary to present some characteristics that must be taken into account, especially in the long-term training process. From this point of view, during the initial training phase, whose main objective is the acquisition of a large number of aptitudes and skills of movement, the goal is the formation and perfection of the GO-KIO system techniques, focusing on positions (SHIZENTHAI), movements (SHINTHAI), grabbings (KUMI-KATA), imbalances (KUZUHI) and entries (TSUKURI) Prior to this, learning particularly the UKEMI procedures (strokes) should be insisted on, which influence the 
correct appropriation of all procedures specific to combat on foot (NAGE-VAZA).

For efficiency, the specific technical elements in the training of the fall will be learned from the simplest executions in the sitting position. The successive contact of the various parts of the body with the surface of the battle is essential in the process of learning and improving the falls. This aspect involves the rolling of the body in a fall so as to attenuate the shock at the contact of the body with the surface of the battle. The first element in the learning of the falls is learning the damping stroke with your arms in the battle surface, which is learned from the dorsal lying position. The damping stroke must be executed with the arms perfectly stretched and the palms facing down; it must be short and very fast, being performed at a fraction of a second before the contact with the ground. Insistence must also be played on the position of the chin, which should be placed in the chest, as well as on the pelvis that should be slightly lifted in order to avoid shocks in landing. Then there will be executed falls from the couching position on the back, sideways and forward, further passing on to the falls from the standing position.

Then falls from the squatting position will be executed, passing on to the foot falls afterwards. As methodical exercises for learning and perfecting the falls, the following can be used:

- from the sitting position, rollings of the body on the back and coming back;

- from the dorsal sitting position, beatings are executed in the battle space;

- from the sitting position, rollings of the body on the back and beating in the battle space;

-from the squatting position, rollings of the body on the back and coming back;

- from the squatting position, rollings of the body on the back and beating in the battle space;
- from the squatting position, rolling forwardsideways and beating;

- from the squatting position, rolling forwardsideways, beating and lifting;

- from the crouching position, falling backward with a jump;

- from the squatting position, falling backward, beating in the space of battle and a jump;

- from the position with the legs apart, slightly semi-flexed, falling back, beating in the battle space and jump;

- from the fighting standing position, falls on the back, forward or sideways with a jump.

For a correct acquisition of the falling technique, multiple repetitions are needed, both without and with a partner; in the training process aiding materials can also be used.

The learning and improvement of guard positions (SHIZEN-THAI) is essential in judo, because if it is not mastered perfectly, it will have repercussions on the way the battle is fought. In the training process, the specialists must insist on the position of the optimal guard position available to each fighter, which is determined by the individual morpho-functional characteristics, as well as by the level of physical training of the fighter. The guard position should be learnt on both sides and the specialists will insist on identifying it for each fighter, ensuring that they have a position that will provide them optimal, maximum balance in attack and defense.

The movements on the battlefield (SHINTAI) can take different shapes, the choice depending on the situation in which the fight takes place. These can be: through normal walking steps, by added steps or by pivoting. When learned, it is recommended that normal walking forward and backward steps should be started with (AYUMI-ASHI). Here specialists must keep in mind the following: while on the move which must be very cautious, the fighter must always have the optimal guard position; the contact of the foot with the mattress should be taken first 
with the tip of the foot, then with the sole and only then with the heel; the foot should move as close as possible to the mattress without being raised too much.

The movements by added steps (TSUGIASHI) will begin with the foot from the direction in which the movement takes place, the first step being extremely important because the counterpart can be launched in this stage. The first step will be executed extremely close to the mattress and the second very rapidly in order to restore the guard position. The pivoting technique (TAISABAKI) will be taught only after the very good acquisition of the other two ways of movement because it is very complex. The learning and perfection of the technique of grabbing ( KUMI-KATA) plays a special role in the training process since their variety is great and the fight for a good grab requires exceptional training.

Training and Improvement Technique (KUMI-KATA) has a great place in the training process, because their greatness is very high, and the fight for a good outlet requires exceptional training.

It is advisable that each fighter knows which is the most efficient grabbing for him because it also depends on the individual morpho-functional characteristics and on the level of development of force and mobility as well. In the beginning, the classical grabbings will be demonstrated and learned, then the other types of grabbings and the executions will be without resistance, then with resistance.

The imbalances (KUZUSHI) and entries (TSUKURI) represent an essential moment of the combat, they are executed simultaneously, and the specialists must place a special emphasis on their perfect acquisition and on the the fighters' developing the sense of the moment. For efficiency, the imbalances must be done in all the directions with an emphasis on the differentiated work of the arms and legs, the execution of misleading movements, at the beginning at a slow pace and then more and more rapidly, as well as on the constant control of the balance. It shouldn't be forgotten that the grabbings, the imbalances and the entries must be carried out in perfect coordination, conditioning each other and maximizing the outcome of the combat.

The method of acquiring and improving the technical procedures in the legs (NAGEVAZA) is the essence of obtaining the highest performance in the combat because it conditions the correct assimilation of all the procedures that result from them and ensures the conditions for the subsequent unfolding of the combat and for obtaining success. It is indicated that for the correct acquisition of these procedures, in the learning phase, specialists should use for beginners fighters with an already well-learnt technique that will be models for them and will contribute to the formation of correct skills from the beginning.

The diversity of the technical procedures in this group demands a continuous training process during the three phases of preparation, namely the study phase of assimilation, the improvement and automation phase. The foot, hip and shoulder technique, as well as the technique of sacrifice require from the specialists maximum efforts to identify for each fighter the most appropriate methods and means of action for the formation of correct and lasting skills that can be easily adapted to the complex demands of the battlefield, taking into account the psycho-physical characteristics of each fighter.

The methodology used to learn, enhance and improve the ground combat technique (NEWAZA) also has a number of peculiarities. First of all, the specialists should take into account that all the three groups specific to ground combat - immobilizations, strangulations and the aricular technique require the execution of four essential phases 
in order to acquire and consolidate a correct technique, namely: the phase of leading the opponent to the desired position, the control phase of the opponent, the phase of cancelling the adversary's liberation movement and the phase of counter-attack at the opponent's attacks, phases that bind to each other and also condition each other. In the training of fighters, it must be remembered that within the ground combat there are no moments of relaxation or any other kind of defensive actions, the mentality of the fighters being centered on the attack combat.

It should also be noted that the immobilization technique will first be acquired, being the starting point for the formation of skills specific to the aricular technique and strangulations. A special role in the success of the immobilization technique has the pressure exerted on the opponent, therefore special attention will be given to this aspect and to the ways in which it is carried out for obtaining success. The technicque of strangulations will be taught after a specific training period of at least six months because it also requires exceptional specific physical training.

From this point of view, it is necessary to insist on the development of the strength of the arms and of the legs, knowing that strangulations can be executed with one arm, with both arms, with one arm and one leg or only with the legs. In the case of the strangulations carried out with the backhands, we highlight that the pressure exerted on the adversary's neck can be applied with the edges of the arms, which will increase the effect of strangulation. The aricular techniques are elements that take the opponent out of combat if they are wellexecuted since he is left without the possibility of using one arm and his chances of success are reduced by half.
These techniques are very complex and dangerous, therefore the training process must be done with great care and only after appropriate physical and psychological training. First of all, the UDE-GARAMI and UDE-HISHIGI-JUJI-GATAME procedures will be acquired, considered as basic procedures, also conditioning the acquisition of other techniques specific to the strangulation technique.

In the process of learning, consolidating and perfecting the judo technique, it will always be born in mind the necessity of observing the principles of learning, as well as those of knowing the morpho-functional particularities of the fighters.

\section{Conclusions}

Judo is a combat sport with special implications for the human body, generating both physical and mental changes, so in the training process it is necessary to take into account the possibilities of adaptation of the body to the demands of this type of effort. The restoration of the human body' $s$ functional capacities and energetic potential taking place after the training programs should be gradually done, and the training programs should be resumed only afterwards [4]. A special role in achieving the objectives of improving the technique specific to judo has the level of physical training that requires a certain degree of development of the basic motor skills, knowing that this level conditions the formation, consolidation and improvement of the motor skills and aptitudes and, implicitly, of the technical training. In the training of the fighters, mastery of a rich system of judo-specific combat techniques ensures the adaptation to the close combat in the conflict areas and creates the conditions for accomplishing the ever-diversified missions of the armed conflicts specific to this millennium. 


\section{References}

[1] Robert Stănciulescu, Studiu privind influența judoului în imbunătățirea performanțelor studenților la disciplina Educație fizică, "Nicolae Bălcescu" Land Forces Academy Publishing House, 2016.

[2] Ion Hantau, Teoria şi metodica judoului, Bucharest, ANEFS, 2005.

[3] Dan Deliu,Tehnici de autoapărare, Discobolul Publishing House, Bucharest, 2016.

[4] Epuran,M., Horghidan,V., Psihologia educaţiei fizice, Bucharest, A.N.E.F.S., 1994. 